\title{
Cargo Cults and Cognitive Apprenticeships: Two Frameworks for Adopting Unfamiliar Curricular Cultures
}

\section{Mel Chua, Olin College of Engineering}

Mel is an engineering education researcher who works with postmodern qualitative methodologies, curricular cultures within and inspired by hacker/maker communities, and engineering faculty formation. She is also an electrical and computer engineer and auditory low-pass filter who occasionally draws research cartoon

\section{Prof. Lynn Andrea Stein, Olin College of Engineering}

Lynn Andrea Stein is Professor of Computer and Cognitive Science at Olin College of Engineering in Needham, Massachusetts. Stein's research spans the fields of artificial intelligence, programming languages, human-computer interaction, and engineering and computer science education. 


\title{
Cargo cults and cognitive apprenticeships: Two frameworks for adopting unfamiliar curricular cultures
}

\begin{abstract}
This theory paper suggests a contrasting pair of frames through which to view faculty attempts to adopt curricular cultures, as when introducing new pedagogies into courses. Attempts that use a cargo cult framing treat novel pedagogies as writ, copying practices without interrogating underlying meaning. In contrast, attempts that use a cognitive apprenticeship framing presume that expertise comes through scaffolded, reflective, and social performance leading toward contextually adaptable mastery. These contrasting frames, supported by case studies, provide a theoretical basis for improved curricular culture change.
\end{abstract}

\section{Introduction: Pedagogical change is curricular culture change}

Educational experiences are embedded in curricular cultures. By curricular cultures, we mean particular sets of assumptions, practices, and skills regarding teaching and learning that are shared by a community, or, in more colloquial terms, "the way we do things around here" with respect to the curriculum. An individual course typically includes a particular set of expectations, roles, activities, artifacts, and underlying assumptions about these aspects that match "how we do things around here."

For example, a traditional lecture-style mechanics course might be typified by what King describes as the "Sage on the Stage" dynamic [1]. This may also include an expectation of weekly tightly-defined problem sets with black-and-white answers, teaching assistant office hours which students are expected to attend only when they have concrete questions, limited lecture attendance, and a strict curve grading system that implies a limited number of top marks. Another lecture class might involve clickers, expectations of both attendance and participation, teaching assistant support for collaborative work on open-ended problems, etc. Although both the classes described above are lecture-style, the first fits within a far more rigid curricular culture than the second.

Often, aspects of such a curricular culture will be shared across an academic department or an academic institution. However, variations can occur at any level of scale. Curricular culture variance may be exhibited in:

- a single session within a course (e.g., a drag racer derby day in contrast with the other lecture-focused weeks in a mechanics course)

- a single course within an institution (e.g. a design-intensive course in an academic program otherwise consisting of applied math problem set work)

- a single department or school within a larger institution (e.g. an experimental degree program within a more traditional university)

- a single college or university within a country or an academic discipline.

As our understanding of impactful learning evolves, many instructors are drawn to explore alternative pedagogies such as flipped classrooms, hands-on exploration, problem-based and 
project-based approaches, case studies, peer instruction, and more. These and other active pedagogies can improve engineering student learning [2]. Effectively deploying any of these approaches entails a shift in curricular culture. Roles, activities, expectations, and artifacts change from one pedagogical approach to another, and so the underlying assumptions faculty members make about teaching and learning must change as well.

Faculty members undertaking such pedagogical modifications sometimes struggle to make the concomitant adjustments to their curricular culture. For example, an instructor might adopt clickers but ask superficial questions (e.g., where answers reflect varying numerical calculations rather than underlying conceptual models) and find that student outcomes do not improve as they had hoped. Schein's depiction of organizational culture differentiates surface-level features from deeper values and assumptions [3]. In the example above, the clicker was a surface-level artifact that the instructor tried to duplicate, but the underlying curricular culture was missing.

Thus, major changes to curriculum, such as the adoption of project-based learning or moving from lecture to studio formats, often involve cultural shifts. Faculty members introducing such curricular changes may attempt to adopt or adapt practices from other institutions whose curricular cultures they wish to emulate. However, attempting to adapt an unfamiliar curricular culture to one's home institutional context is a daunting task. The question of where to begin and how to make sense of a foreign curricular culture can be overwhelming. We approach this topic by talking about a faculty member's approach to the beginning stages of this cultural acquisition. Specifically, we consider the aspects that might make an approach more or less skilled and likely to be successful when proceeding in the face of this sort of unknown complexity.

This paper presents a pair of models drawn from the social and learning sciences that help to make sense of faculty approaches to pedagogical — and corresponding culture - change. These contrasting models provide alternative frames for the diverse approaches taken by faculty members, informing our understandings of why some attempts succeed and others do not. Why do some attempts to incorporate new pedagogies flourish while others struggle to take root? How might we understand the ways various environmental features can influence which of these approaches faculty take, and how we might distinguish the former from the latter?

In this paper, we use the sociological concept of "cargo culting" and the learning theory of "cognitive apprenticeship" as frames for exploring case studies of curricular culture change. The use of multiple lightweight case studies can provide a way to triangulate on understanding a more general phenomena [4]. The two frames presented for these case studies provide alternate understandings of an instructor's experience in moving towards new pedagogies and curricular cultures: cargo-culting affords framing cultural acquisition as one-shot adoption of a frozen, untouchable, and complete practice, whereas cognitive apprenticeship affords framing it as ongoing acquisition of proficiency in a shifting, socially constructed practice. Reality, of course, often lies somewhere in between. While the former frame treats new pedagogies as complete and sometimes inscrutable packages, the latter opens the way for adaptation and integration.

Articulating these two frames and examining cases through their vantage points provides tools to support cultural adoption and adaptation and instructors' continued progress towards mastery.

\section{Faculty members as novices in new cultures}


The Dreyfus model of skill acquisition depicts mastery as the ability to independently navigate a domain's complexity [5]. In the context of curricular cultures, a novice is someone who has yet to develop the ability to independently navigate the complexity of the culture that is new to them. While faculty members may be experts in their academic domain and their home curricular culture, learning to teach in a radically different way (going from lecture to studio, transitioning between institutions, etc.) involves becoming a novice in an unfamiliar type of complex learning environment.

For instance, a faculty member who is an expert at conducting their own research projects in mathematics may be a novice at helping students determine their own mathematics research problems. Similarly, walking into a studio classroom for the first time can be overwhelming for faculty members used to set boundaries of authority and information; they may know the material and be expert lecturers, but with respect to the curricular culture of an unfamiliar classroom format, they are beginners. Or again, a faculty used to teaching in their home institution might be stymied by the culture of the college they are visiting during their sabbatical.

One defining feature of novices is that they require scaffolding in order to move forward [5]. For example, consider the writing styles of beginner cookbooks, where measurements and timings are carefully given. In contrast, those who have greater mastery can improvise with more general instructions, such as "add any green vegetable" or "roast until done." Novices need scaffolding because the complex contexts they are trying to learn their way into are contexts that they cannot yet decipher and fluently move within. In contrast, those with greater mastery are able to parse complex contexts and to focus on the most relevant — to them, most salient — aspects. Novices, faced with an overwhelming amount of context, often search for anything that they can understand and do. They tend to seek a simpler task they can execute, in the hopes that it will get them towards their goal. In the remainder of this paper, we scrutinize the ways in which faculty novices make sense of these "simpler tasks" and their attempts to execute them.

\section{Cargo cults vs. cultural apprenticeships: two frames for understanding the acquisition of curricular cultures by novices}

This section describes cargo culting and cognitive apprenticeships, the two frames we use to articulate different faculty approaches to adopting curricular cultures unfamiliar to them. The first can easily lead to being stuck, possibly without even recognizing one's failure to progress. The second is more likely to lead to eventual success of some sort, regardless of the surrounding circumstances; it is a stance of constant growth and reflexivity.

Cargo culting is the rote copying of surface features separated from context and community. Cargo cult theory was developed by sociologists observing Pacific tribes constructing imitation airstrips and wooden headsets in the hopes that unknown gods would rain crates of supplies on them just as they did for the Allied and Axis armies in WWII [6][7]. While the details of Pacific tribe behavior and sociologists' interpretations thereof have been called into question by later researchers, its central image is both compelling and efficacious. Novice attempts to replicate desired outcomes by propitiating inexplicable processes certainly occur in our own native environments. Students in introductory programming classes, for example, often resort to 
repeated code modifications without rhyme or reason, simply hoping that the next change will be the one that satisfies the compiler deity. The salient features of cargo culting, then, are:

1. The process is holistic, choate, and mysterious; it either works or it doesn't. Adopting the appropriate process will lead to the desired outcome, which can only be judged by experts.

2. The relevant portions of the process - those sufficient to produce success - are both observable and (relatively) context-independent.

3. Success rests with the individual, who is either worthy (able to perform the appropriate practice and achieve the desired result) or not.

Cargo culting, simpliciter, is surely an oversimplification of faculty practice when adopting curricular culture. Yet we do see a close approximation to cargo culting as an initial approach by many faculty members. Comments such as "give me your curriculum," "tell me what I need to do," and "never mind the why; just tell me how" are commonplace in our experiences of curricular culture change [8]. These requests elide the necessity of context-appropriate adaptation, an integral part of curricular culture change.

In contrast, our second frame acknowledges learning and culture transfer as a process of supported practice, sensemaking, and growth. Cognitive apprenticeship is scaffolded participation in meaningful work embedded in authentic cultural practice alongside multiple seasoned mentors. Cognitive apprenticeship theory was developed to describe the enculturation of novices into communities of practice [9][10]. It begins from the assumption of a learning continuum, in which novices gradually develop skills — both of praxis and of sensemaking and grow through various degrees of increasing mastery. Cognitive apprenticeship involves explicit or implicit reflection, articulation of rationale along with behavior, and progression from legitimate peripheral participation to increasingly autonomous and creatively adaptive practice. Salient features of cognitive apprenticeship include:

1. Explicit interrogation of assumptions is encouraged as a necessary part of growth.

2. Practice is explicitly social, and one learns from being embedded in a community of learners. Those with greater expertise are simply further along the continuum than others.

3. Increased ability to perform and increased ability to make sense of, adapt, and improvise are interrelated and acquired in tandem.

\section{Principles that differentiate cargo culting from cognitive apprenticeship}

In this section, we unpack the salient features mentioned above into three principles that differ between cargo culting and cognitive apprenticeship framings of curricular culture change. Adoption or non-adoption of these principles can either support successful approaches (in the case of cognitive apprenticeship) or limit their efficacy (when faculty appear to practice cargo culting). We use case studies to make these principles and their contrasts more concrete and familiar to engineering education contexts.

The three principles we will discuss are interrogation of assumptions, the belief that there is knowledge out there to be found in community, and the notion that everything is editable. In the 
sections that follow, we will briefly describe each principle and give examples of a cargo cult instance and a cognitive apprenticeship instance. Case studies are drawn from ethnographic fieldnotes, interviews, and documents focused on or written by faculty at a small teaching college's engineering program, though some of these faculty described experiences they had encountered at other institutions. These faculty were all new to a cultural aspect of the college's curriculum in some way: this included visiting faculty who had not experienced the college's curricular culture before, new faculty just starting their time at the college, and experienced faculty who were moving into new roles.

\section{Principle 1: Assumptions are to be interrogated}

The first principle is about sensemaking in context as it pertains to practice. Specifically, it concerns interrogation of meaning within the practice: what are my assumptions as I work to decipher this new culture, and are they correct in the sense of being socially shared by fluent participants in the culture? This is similar to when a new language learner constantly inquires as to whether a particular word has different connotations in their new culture as in their home one. A faculty member exhibiting interrogation of meaning tends to ask, and be asked about, what they might be assuming, what biases they might carry, and how they can check if their hypotheses are correct.

Cargo culting behavior does not reflect this principle. There is no interrogation of meaning, only copying of surface features that often make little difference, as the island natives did when they built wooden headsets that could never connect to an airplane dispatcher. If an action works, it does so randomly; sometimes the novice does not know whether their attempt has worked or not. This is the sort of behavior students engage in when they randomly power-cycle lab equipment instead of debugging it to make it work, or throw buzzwords into papers to see if they will yield a higher grade.

One example of cargo-culting in a faculty context comes from a college's early experiments with team-taught courses. The engineering faculty had decided that "interdisciplinary" courses would be a good idea, and had heard of other schools running such courses by having professors from different disciplines teach together. In this case, the surface feature was "team teaching;" the faculty assumed team teaching would automatically make a course "interdisciplinary." They did not inquire as to what an "interdisciplinary course" meant beyond that, or how team teaching might or might not facilitate it, or how else (other than team-teaching) an interdisciplinary course might be successfully run. Needless to say, the first round of team-taught courses largely fell flat, as various faculty were summarily placed in a classroom together and told to be "interdisciplinary" without much further guidance.

In contrast, a cognitive apprenticeship approach frames the same exploration as an interrogation of meaning, knowing that their initial guesses are likely to be wrong. The question is what the observable features of a culture mean, and how they might have come to have that meaning. An example of this comes from a faculty member on sabbatical who wanted to learn about a popular design course outside their domain of engineering expertise, with the hopes of eventually being able to help instruct it. They entered the course asking to be treated as a student auditing the 
class, with the assumption that they were presently unable to help teach it. Here, the meaning being interrogated was the meaning of "able to help teach" for this specific course.

During the course of the semester, that faculty member kept asking and being asked what it might mean to "be able to teach this course." They found that their assumptions were untrue, and while they were not terribly experienced in the field itself, some of their prior experiences in other fields was highly applicable. As they continued experimenting and interrogating what it meant to "be able to teach the course," they shifted from a "student-like" role into a more "instructor-like" role, ultimately ending the semester as an informal member of the teaching team.

\section{Principle 2: There's knowledge out there to be found in community}

The second principle concerns the notion of where and how one might find knowledge. The notion that knowledge is out there to be found, and does not need to be invented, is a key one. It is the assumption that role models might exist to help one invent one's own notion of oneself. It is the notion that, while the specific path one wishes to take to learn this new curricular culture might not yet exist, there do exist paths and path-segments one can find and use to get closer.

A cargo cult approach that lacks this principle can be fostered by isolation. In the case of the islanders, it was physical and informational isolation, and they were able to persist with their "wooden radios" because nobody stopped them to point out that it wasn't working. In the faculty space, this looks like a heap of written reflections from visiting faculty about how they were "the only one of their kind" at their home institution; these stories of isolation come with the assumption that it is my job, and my job alone, to heroically reinvent the wheel. There is no useful knowledge out there to be found; nobody else who could possibly help me is accessible. Furthermore, it is knowledge that I lack and need, rather than community that can give me an evolving context where I might place that knowledge in dialogue. I simply need to know the "how," and the "who" and "why" are less important.

In contrast, a cognitive apprenticeship approach does not imply that the faculty member is in contact with a community right now, but that they believe they could someday find that community, and that they are actively looking for one, and that such a community could be of benefit. The community may not be directly in the cultural intersection the faculty member is a novice at learning; it may end up being patched together from adjacent arenas. It may also not be current; a faculty member might learn from a community of writers from ages long past. Nevertheless, they are not the first ones; they are not alone, and there is something out there in the journeys of others - that might be useful to them. When that community is found, they can take up some of the job of fostering that faculty member's growth, helping them interrogate meaning (as with the first principle), and scaffolding appropriate tasks for them to undertake. In all of these engagements, fixed bits of knowledge are not the primary thing sought; sensemaking skills that will enable the reinterpretation and generation of new knowledge are more valuable.

A small case study of the cognitive apprenticeship approach concerns a new faculty member who began at their current institution as a postdoc. They were assigned to co-teach a software course that had been run by the same professor for an extended length of time. Although the younger 
professor had different ideas about how the course might be taught, they also quickly realized their more experienced colleague had a wealth of knowledge on both the course topic and their new institution's curricular culture. The young professor spent the semester learning from the older one, simultaneously searching for and drawing from other sources in order to develop their own approach. Differences between the two professors' approaches did arise, but were not seen as problematic. Rather, they became opportunities to interrogate reasoning and question assumptions, and both professors learned a great deal from their interactions. Several terms later, the more experienced professor handed off the course to the new faculty member under the condition that they transform the course to match their new ideas. The younger professor had, in a way, "graduated" into being culturally fluent enough to change the culture they had once been a novice within.

\section{Principle 3: Everything is editable}

The third principle is about the perceived limits of one's agency. The notion that everything is editable expands the realms of possibility for what aspects of the world can change, and how. In the context of curricular change, this principle means that constraints on curricular change are situated and interconnected rather than absolute statements in isolation; it is not that one "can't change X," but that one "can't change X without somehow affecting Y." Furthermore, the notion that everything is editable implies that while Y may be out of scope at present, things could be renegotiated such that $\mathrm{Y}$ could also change. Since one sort of mastery entails the ability to adapt both oneself and one's environment [5], the mindsets engendered by this principle foster the acquisition of such mastery.

Adopting this principle does not necessarily mean that everything is equally accessible or easy to edit, or that others will agree that one's agency can or should extend to particular domains. However, it does mean that these sorts of boundaries can at least be questioned and challenged. There are tradeoffs to attempting to change certain parts and aspects of the world, and these tradeoffs can sometimes be severe. However, the decision on whether or not to engage with these tradeoffs is an active choice.

A cargo cult approach that lacks this principle can be fostered by two techniques described by Bruner: narrative seduction and banality [11]. Narrative seduction refers to the insistence of someone in power that their interpretations of events are the only correct ones, and cannot be questioned. Bruner's original paper refers to a document author; in the case of curricular change, the people in power might be administrators or senior faculty members. The second technique, banality, refers to the portrayal of something as so commonplace that it should be ignored. For instance, perhaps everyone "knows" that students are a certain way, or that engineering students "should" enter with a certain set of prerequisites. Questioning foundational assumptions about engineering and engineering knowledge has emerged as an important type of contribution in engineering education research [12].

One example of a cargo cult approach that illustrates the lack of this principle comes from a case where two graduate TAs were assisting with a first-year project-based course. Several of their discussions centered around whether they could propose particular modifications to the curriculum, which had assignments that they felt could be improved. On some of these 
occasions, the TAs concluded they could not make those suggestions. Instead, they needed to deal with a system that they could not modify, a curricular machine constructed and controlled by those with more power. This sort of hands-off fatalism stood in contrast to other occasions when the same TAs concluded that they could suggest the modifications, but that this would entail tradeoffs they didn't want to handle at the time, and framed their lack of action as a choice to not engage. Framing actions as choices as opposed to compulsions acts as an implicit reminder that there were (and possibly still are) other choices, and that future choices may be made differently.

In contrast, a cognitive apprenticeship approach sees the world not only as socially constructed, but socially constructed by the sorts of people that they either are or could someday become. The attitude is one of openness: this space is open to me, and I can engage with it. Furthermore, I can build my ability to engage with it through the act of engagement itself. Constraints are still present, but they no longer constrain in an absolute manner; instead, they shape the costs of tradeoffs that a person has to choose between. When a faculty member decides to engage with and deconstruct the boundaries and categories presented to them, they exhibit agency over those boundaries.

An example of deconstruction that exemplifies the cognitive apprenticeship approach concerns a senior faculty member who was spending their sabbatical at a different institution. This faculty member was teaching a studio-based technical class, which was atypical for their host institution. They received a form querying whether the class was a lecture or a lab, so that their class could be assigned to an appropriate classroom space. The faculty member's response was that it was neither, and that they needed a studio-style classroom with tables for group work. The host institution responded that there was no such classroom on campus that could accommodate all of the students enrolled in the course. Instead of interpreting those constraints as a sign that their desired pedagogical approach was infeasible, the faculty member simply created a pop-up studio-style space in a wide hallway and taught their class from that space for the term. In this case, the faculty member's ability to adapt a curricular change to their host institution was realized they had the agency to edit the physical layout of their host campus, and thus went about doing so.

\section{Conclusion: There is no magic; we are all learners}

As shown above, these two frames provide contrasting views of what faculty members are doing when they adopt pedagogies and change curricular culture. When viewed as a cargo cult activity, faculty members adopt wholesale the practice of others, without regard to the particularities of their home contexts and without further interrogation of motivation. While few actually engage in this kind of unthinking adoption, pedagogical change language focused on dissemination often suggests only minor deviation from this model. In contrast, the frame of cognitive apprenticeship encourages ongoing interrogation of rationale, context, and praxis. It also suggests embedding in a community and climbing a continuum of mastery, and both promises and requires increasing contextual sensitivity to enable appropriate adaptation and improvisational innovation.

Just as students can have good learning strategies independent of their learning environment, but a good learning environment can foster the development and usage of those strategies, the same 
is true for faculty. The principles described above can be utilized independent of the background or situation of the novice faculty member. In other words, while a faculty member's environment might encourage cargo culting or cognitive apprenticeship for a particular instance of learning a new curricular culture, it is up to the faculty member which approach to utilize. While we certainly encourage administrators and institutions to create environments that foster cognitive apprenticeship for faculty in this regard, and while such environments may make the work significantly faster and easier, it is not strictly necessary in order to move forward at all.

The realization that these principles are not strictly context-dependent leads to a tremendously agentic position for faculty learning a new curricular culture. It means that, even though the context may be unfamiliar and uncertainty might be high, there is no such thing as a situation from which one can't learn. Furthermore, a faculty member is both never done learning, and never starting from zero - the image is one of continuous improvement and ongoing development. There is no "magic" that transforms a novice in a culture into an expert in that culture; as we often tell our students, the only way to get good at something is simply to start doing it, and you'll develop along the way. This statement is equally true - and encouraging for faculty looking at the daunting but crucial task of learning a new curricular culture to somehow adopt it or to change their own.

\section{References}

[1] King, A. (1993). From Sage on the Stage to Guide on the Side. College Teaching, 41(1), 3035 .

[2] Smith, K. A., Sheppard, S. D., Johnson, D. W., \& Johnson, R. T. (2005). Pedagogies of Engagement: Classroom-Based Practices. Journal of Engineering Education, 1-15.

[3] Schein, E. H. (2010). Organizational Culture and Leadership, 4th ed. San Francisco: JosseyBass.

[4] Stake, R. E. (2005). Qualitative Case Studies. In N. K. Denzin \& Y. S. Lincoln (Eds.), The SAGE Handbook of Qualitative Research (3rd ed., pp. 443-466). Thousand Oaks, CA: SAGE Publications, Inc.

[5] Dreyfus, S. E., \& Dreyfus, H. L. (1980). A Five-Stage Model of the Mental Activities Involved in Directed Skill Acquisition. Operations Research Center, University of California Berkeley.

[6] Worsley, P. (1957). The trumpet shall sound: a study of "cargo" cults in Melanesia. London: MacGibbon \& Kee.

[7] Lindstrom, Lamont (1993). Cargo cult: strange stories of desire from Melanesia and beyond. Honolulu: University of Hawaii Press. 
[8] Chua, M. \& Dringenberg, E. (2014). The quest for the Mythical Phoenix: Attendee narratives at an engineering education faculty workshop. Presented at the Frontiers in Education Conference, Madrid.

[9] Collins, A., Brown, J. S., \& Newman, S. E. (1987). Cognitive Apprenticeship: teaching the craft of reading, writing, and mathematics. (Research No. 403) (pp. 1-37). Champaign, IL: University of Illinois at Urbana-Champaign.

[10] Collins, A., Brown, J. S., \& Holum, A. (1991). Cognitive apprenticeship: making thinking visible. American Educator, 6, 38-46.

[11] Bruner, J. S. (1991). The Narrative Construction of Reality. Critical Inquiry, 18(1), 1-21.

[12] National Engineering Education Research Colloquies. (2006). The Research Agenda for the New Discipline of Engineering Education. Journal of Engineering Education, 95(4), 259-261. 